\title{
Study of self potential anomalous fluctuations in a seismic active zone of Lucano Apennine (southern Italy): recent results
}

\author{
G. Colangelo ${ }^{1}$, V. Lapenna ${ }^{2}$, and L. Telesca ${ }^{2}$ \\ ${ }^{1}$ Dipartimento Infrastrutture e Mobilità, Ufficio Difesa del Suolo, Regione Basilicata, Potenza, Italy \\ ${ }^{2}$ Istituto di Metodologie per l'Analisi Ambientale, CNR, C.da S.Loja, Tito, Italy
}

Received: 30 June 2008 - Revised: 28 August 2008 - Accepted: 1 September 2008 - Published: 16 October 2008

\begin{abstract}
Geoelectrical fluctuations measured in seismic areas have been attributed to stress and strain changes, associated with earthquakes. The complex nature of this problem has suggested the development of monitoring stations in order to perform geophysical monitoring for a long time period and with a high sample rate. In this paper, anomalous geoelectrical fluctuations of SP signals recorded in the S. Loja basin, Lucano Apennine chain by Tito and Picerno stations, and linked with seismic activity, are analyzed and discussed.
\end{abstract}

\section{Introduction}

The scientific research applied to earthquake dynamics has shown an increasing interest in investigating geophysical signals measured in seismic areas in order to get important information about the relation between the state of stress and strain in a seismic active area. Geoelectrical variations may be useful to monitor complex phenomena related to earthquakes (Johnston, 1997; Park, 1997), since variations in the stress and fluid flow fields can produce changes in the selfpotential field (Scholtz, 1990). Therefore, investigating these induced fluctuations it is possible to get information on the governing mechanisms both in quiescent conditions and during intense seismic activity.

During the last decades many anomalous patterns in the electrical signals were observed (Raleigh et al., 1977; Varotsos and Alexopoulos, 1984a, b; Varotsos et al., 1993). Technically a self-potential time series is a sequence of voltage differences measured with a fixed sampling interval using a receiving electrode array. The field procedures and the equipment involved in these measurements are well known, be-

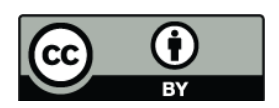

Correspondence to: L. Telesca

(luciano.telesca@imaa.cnr.it) ing currently used in the geoelectrical prospecting. During a geoelectrical soundings, where a current is injected into the ground, it represents the noise (Lapenna et al., 1994). On the other hand when we are using a passive measurement technique (i.e. without energizing system), it is the signal.

The SP method has found large application in geothermal, environmental, and engineering applications to locate and delineate sources associated with movement of fluids and groundwater (Ogilvy et al., 1969; Corwin and Hoover, 1979; Sharma, 1997, and references therein). Furthermore other significant applications can be found in the geophysical survey of volcanic and tectonic areas (Di Maio and Patella, 1991; Lapenna et al., 1994; Di Maio et al., 1997). The origin of self-potential in the subsurface is caused by a wide range of processes which are not well understood at this time. However the principal types of source mechanism are the electrofiltration potential, the thermoelectric potential, the electrochemical and mineralization potential (Sharma, 1997).

In near surface geophysics the most relevant phenomenon which could originate the self-potential anomalous field is known as electrofiltration or streaming potential. It refers to the electrical signals produced when a fluid flows in a porous rock as a consequence of a pore pressure gradient. The phenomenon is generated by the formation in the porous ducts of a double electrical layer between the bounds of the solid, that absorb electrolyte's anions, and cations distributed in one diffused layer, near the boards. When the fluid, subordinate to pressure gradient, flows, it transports a part of the cations, giving on one side an excess of positive charges. Then, it develops an electric field induced along the length of the duct and the associated streaming potential, that it is generated to the duct's ends (Fig. 1).

In this paper we present some examples of self-potential time series anomalies coming from the geoelectrical monitoring network installed S. Loja basin, in a seismic active

Published by Copernicus Publications on behalf of the European Geosciences Union. 


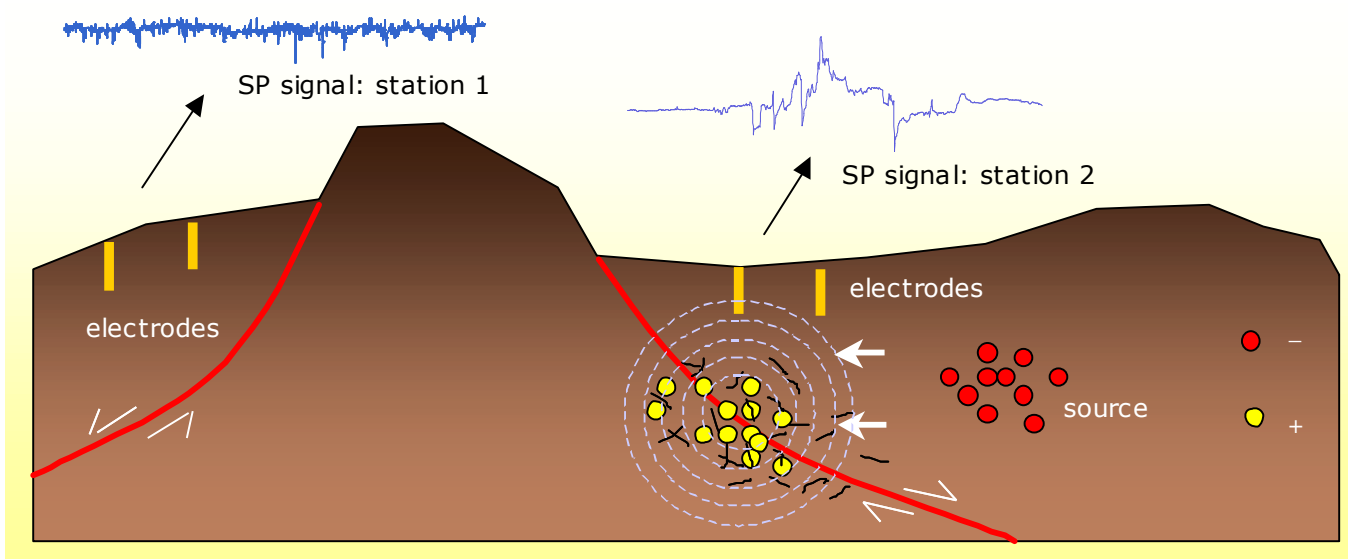

Fig. 1. Electrokinetic process as possibly explanation of SP signals generation.

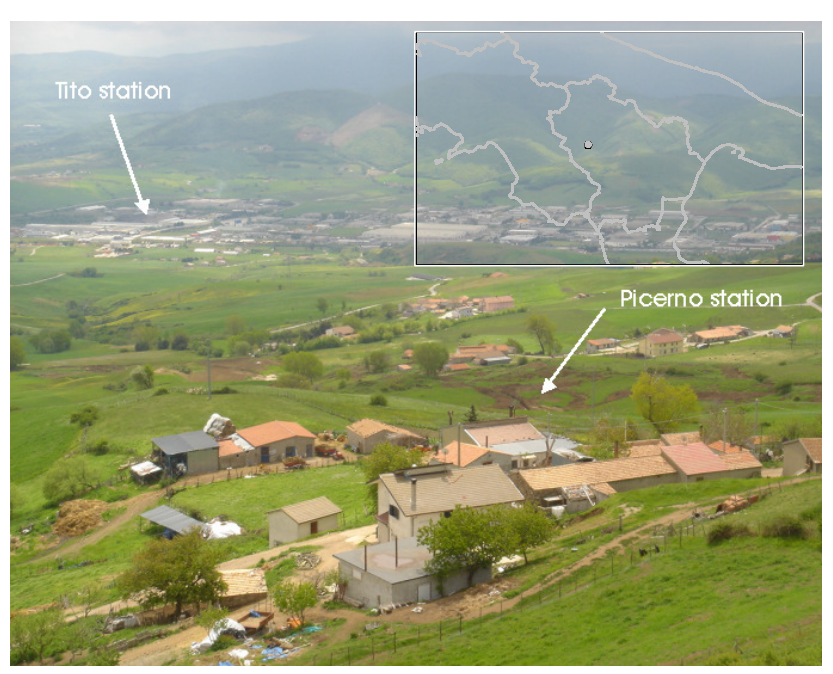

Fig. 2. Geophysical stations in the S. Loja Basin: Tito and Picerno. The remote stations are equipped to detect vertical and horizontal component of the electric field respectively in Tito and Picerno station.

area of the Southern Apennine chain (Balasco et al., 2001). The aim of this monitoring network is to investigate the possible correlation between electrical anomalous patterns and local seismicity.

\section{Geological and seismological settings}

The remote stations are located on Southern Apennine chain, a fold-and-thrust belt built on from late Oligocene to Pleistocene. The chain is mainly composed of MesozoicCenozoic sedimentary cover from the Ligurian oceanic crust and the western passive margin of the Adriatic plate, and of the Neogene-Pleistocene piggyback basin and foredeep de- posits of the active margin. Recent shortening occurred at the belt front deforming Pleistocene sediments and volcanics whereas widely documented extension is still active along the Apennines axis. Major extensional features are located along the Tyrrhenian side of the chain. The belt is also affected by Plio-Quaternary strike-slip faults (Schiattarella, 1998, and references therein).

From the Tyrrhenian Sea to the Adriatic (Apulian) foreland, and from the top to the bottom of the wedge, the following tectonic units are observed (Pescatore et al., 1999, and references therein): (1) Jurassic to Oligocene polydeformed ophiolitic units, unconformably covered by syntectonic deposits, early Miocene in age (Ligurian units); (2) a carbonate platform unit (Campania-Lucania platform), whose age ranges from late Triassic to early Miocene; (3) several units mainly composed by deep-sea sediments, ranging from early Triassic to lower-middle Miocene; (4) a frontal imbricate fan made up of Cretaceous to lower Miocene deep-sea marls, shales and sandstones, covered by middle to upper Miocene syntectonic deposits; (5) Pliocene to Pleistocene foredeep clastic deposits; (6) the Apulian carbonate platform, which has been partly incorporated at the base of the orogenic wedge, forming toward east the less deformed foreland area.

From the seismological point of view, the CampanoLucano sector of the Southern Apennines chain is one of the most active areas of the Mediterranean region. In particular on February 1826 an earthquake, reaching up to VIII degree on the MCS scale (Alessio et al., 1995), hit the village of Tito where are located the geoelectrical stations (Fig. 2). One of the most historically relevant events, the 16 December 1857 (I=XI MCS) normal-faulting earthquake (Mallet, 1862), occurred close to Marsico Nuovo village in Val d'Agri. On 23 November 1980 (Ms=6.9), a large normal-faulting earthquake occurred in the nearby Irpinia area. Seismic activity occurred after the 1980 event consisted of medium intensity events $(\mathrm{M}<5.5)$ located close to the border between 


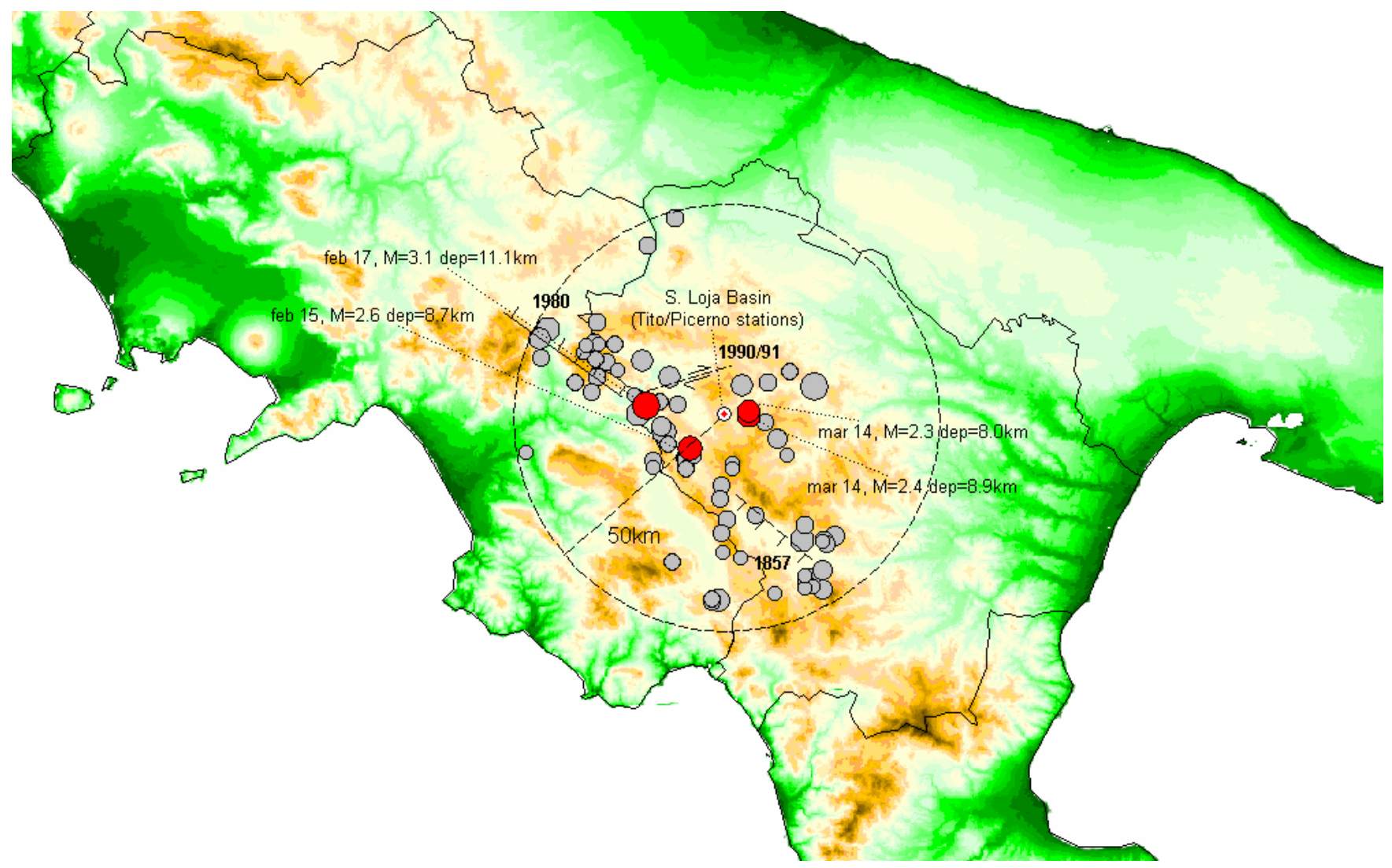

Fig. 3. Seismicity map of the investigated area (January-April 2007, $r=50 \mathrm{~km}, 1.6<\mathrm{M}<3.1$ ) with earthquakes extracted using Dobrolowsky method. The map shows the normal fault system of Irpinia - Val d'Agri area and the strike slip fault of Potenza area.
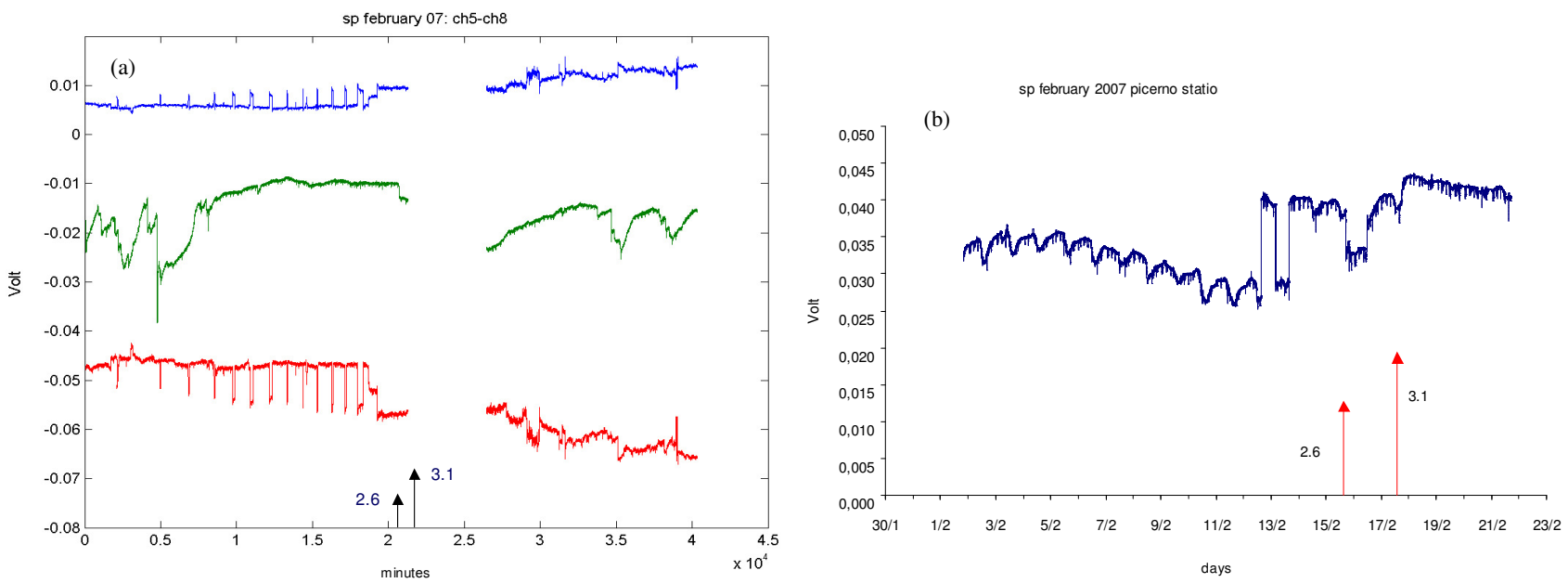

Fig. 4. Self Potential signals recorded at Tito and Picerno stations during February 2007. Picerno station presents sharp increase of SP signals before the earthquakes recorded on $15(\mathrm{M}=2.6)$ and 17 February $2007(\mathrm{M}=3.1)$. Tito station does not show significant variations.

Campania and Basilicata regions (Alessio et al., 1995). The 5 May 1990 (MD=5.0, INGV - National Institute of Geophysics and Volcanology) and the 26 May 1991 (MD=4.7) earthquakes took place to the north of Potenza town (Ter- tulliani et al., 1992). These events have been generated by a strike-slip fault system with WE direction, perpendicularly oriented toward the Apennine chain (Ekström, 1994), located in such a way to limit toward north and south two 

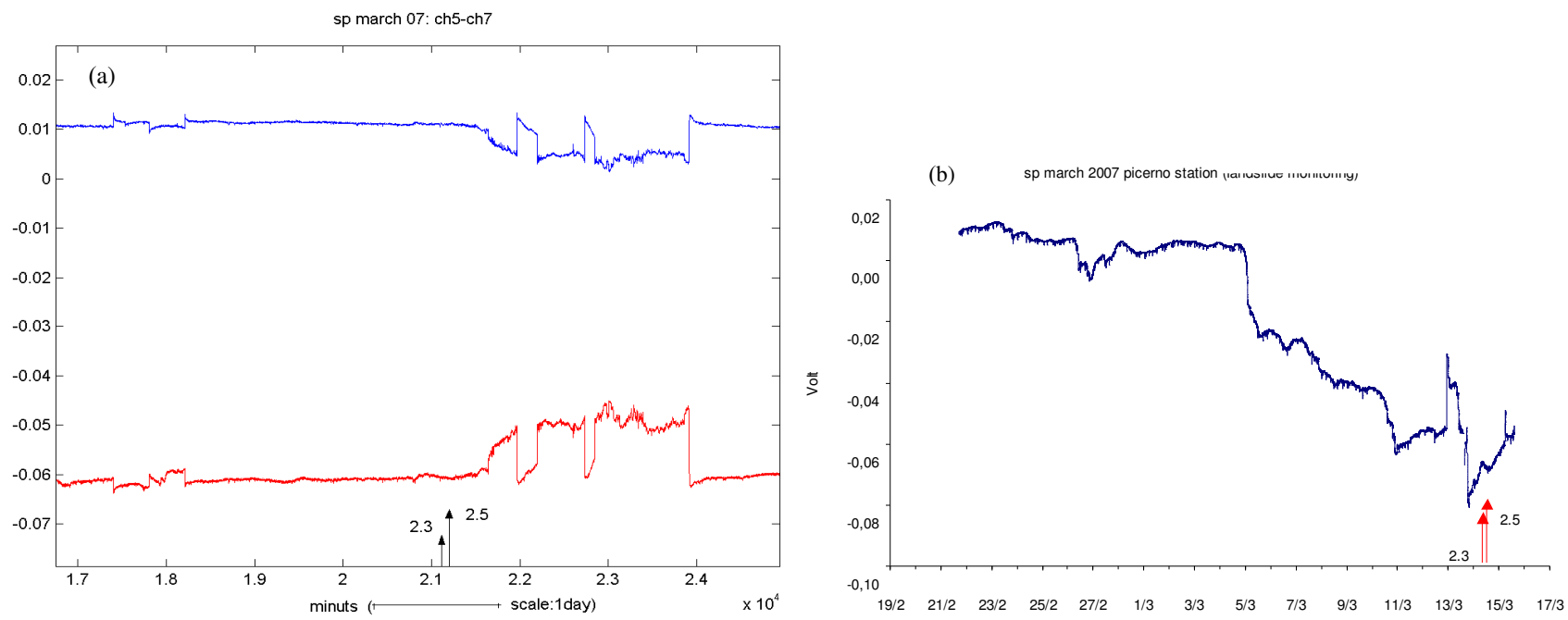

Fig. 5. Self Potential signals recorded at Tito and Picerno stations during March 2007. Picerno station presents sharp increase of SP signals before the earthquakes recorded on 14 March 2007 (M=2.3-2.5). Tito station shows sharp variations one day after the seismic events occurred on 14 March 2007.

rain 12-18 february 2007

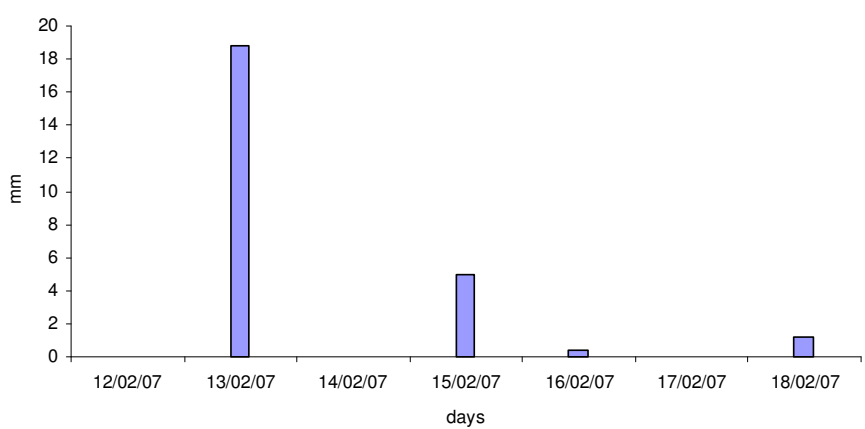

Fig. 6. Rain events recorded during February 2007 (www.alsia.it).

great seismogenetic faults that caused the 1857 Val d'Agri and 1980 Irpinia earthquakes respectively.

\section{Results and discussion}

In this paper we consider the data recorded by Tito and Picerno stations located in Basilicata Region, Southern Italy (Fig. 2). The remote stations are equipped with a multielectrode array to detect the time variation of SP. The SP signals are measured by non-polarizable electrodes (SDEC electrodes, $\mathrm{Pb} / \mathrm{PbCl} 2-\mathrm{NaCl}$ ) linked to a multimeter (Keithley Instruments model 2701, with plug-in switching modules model 7702). The multimeter is a $61 / 2$ digit highperformance data acquisition system, the differential multiplexer provides 40 channels of 2-pole input, or 20 channels of 4-pole input. In order to improve the contact between the electrodes and the ground the bentonite has been used. Both the station are located into an alluvional basin (S. Loja Basin) but they present significant differences: (i) Tito $(40.601 \mathrm{~N}$, $15.724 \mathrm{E})$ is designed to detect SP signals along vertical dipoles with a maximum length of $20 \mathrm{~m}$ (Colangelo et al., 2005); (ii) Picerno (40.6325 N, 15.7062 E) is designed to record SP signals along horizontal dipoles with a maximum length of $35 \mathrm{~m}$.

The analysed period is January-April 2007, during which a few seismic events that possibly induced strain effect in the investigated area were recorded (www.ingv.it) (Fig. 3). The events were extracted from the INGV catalogue (www.ingv. it) using the Dobrovolsky's selection criterion (Dobrolovsky, 1978; Montgomery and Manga, 2003):

$r=10^{0.43 M} \mathrm{~km}$ 


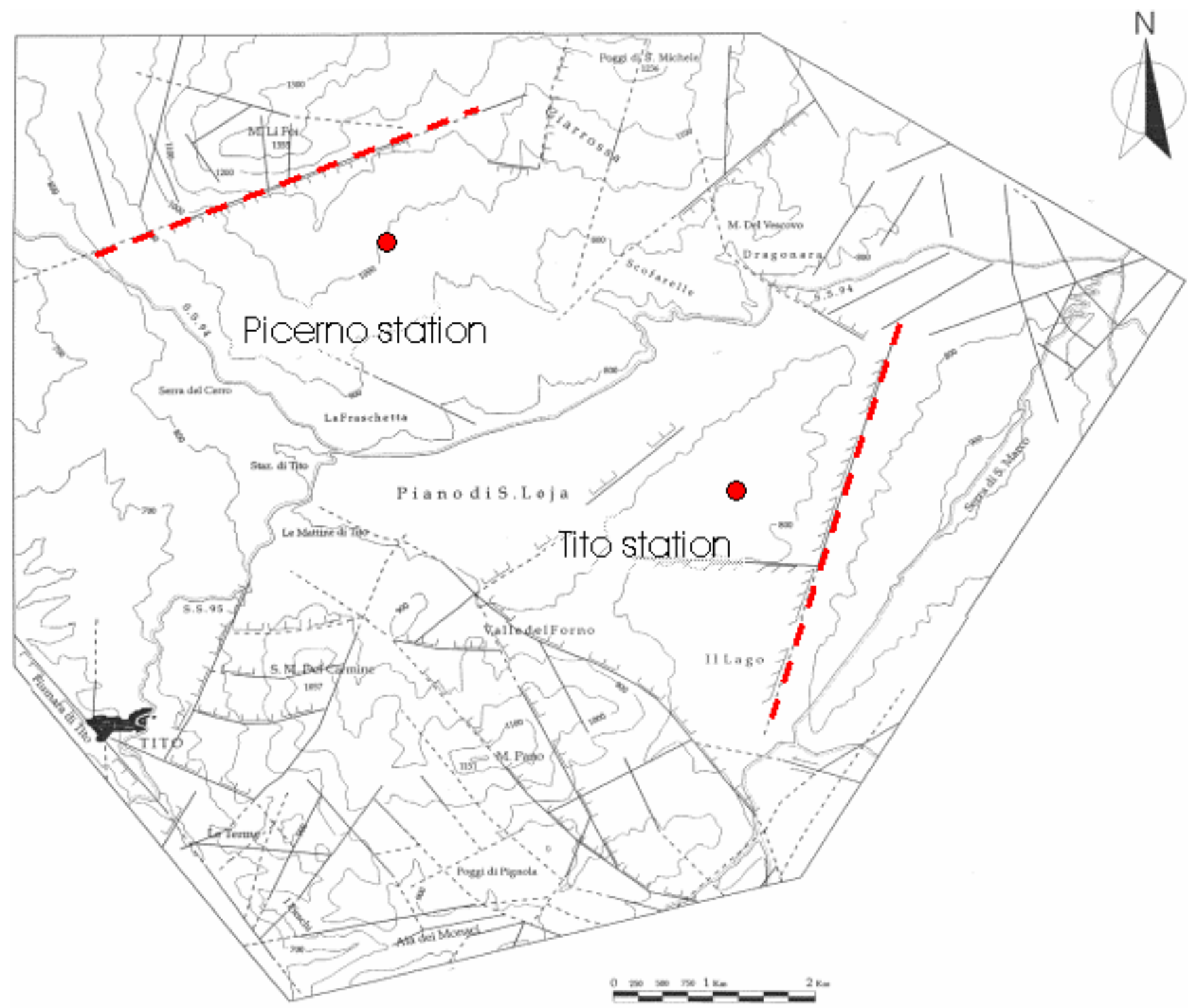

Fig. 7. Tectonic map of the investigated area (Coviello, 1999, modified).

where $M$ is the magnitude and $r$ is the strain radius larger than the distance $R$ between the epicenter and the station.

The selected events occurred in the period FebruaryMarch 2007. In particular, on 15 and 17 February two earthquakes were recorded with magnitude 2.6 and 3.1, respectively.

During this period, the SP fluctuation recorded in Tito station did not show significant variations (Fig. 4a), while the SP measured at Picerno station present a sharp increase before the occurrence of the two seismic events (Fig. 4b). In particular, two anomalous fluctuations in SP time series are recorded 12 and 13 February 2007.

The fluctuations observed from 1 February to 12 February are clearly correlated with the temperature.
On 14 March 2007 two earthquakes with magnitude 2.3 and 2.4 occurred in the investigated area. The epicenters were very close to the remote stations $(<5 \mathrm{~km})$. Both the stations present anomalous fluctuations of SP data (Fig. 5). In particular, Tito SP data show increasing significant variation the day after the two seismic events, lasting for two days approximately (Fig. 5a). Picerno SP data show strong variations (about $40 \mathrm{mV}$ ) before the seismic events (Fig. 5b).

The analysis of precipitations recorded in the investigated area shows that a clear correlation between SP variation and rain can be viewed in February 2007 (18.8 mm on 13 February 2007) and no correlation between SP variations and rain during March 2007 (Fig. 6).

Observing the tectonic map of the investigated area (Fig. 7) it is possible to identify two main faults on the border 
of S. Loja Basin. However, it is possible to see the position of the remote station at the opposite borders of the basin.

\section{Conclusions}

Anomalous fluctuations of SP signals are recorded close to local earthquakes occurred in the investigated area. In February 2007 no clear correlation between SP anomalies and earthquakes can be stated because of the rain; while the variations observed at both the stations Picerno and Tito during March 2007 could be very probably linked to stress and strain changes followed by earthquakes recorded on S. Loja Basin.

The results presented in this paper can be considered as a case study, because they could be relatively few to draw general conclusions, but surely they encourage the monitoring and the study of SP signals in this seismic active area of southern Italy.

Edited by: P. F. Biagi

Reviewed by: G. Martinelli and another anonymous referee

\section{References}

Alessio, G., Esposito, F., Gorini, A., and Porfido, S.: Detailed study of the Potentino seismic zone in the Southern Apennines, Tectonophysics, 250, 113-134, 1995.

Colangelo, G., Lapenna, V., and Telesca, L.: Vertical dipoles to detect self potential signals in a seismic area of southern Italy: Tito station, Nat. Hazards Earth Syst. Sci., 5, 667-671, 2005, http://www.nat-hazards-earth-syst-sci.net/5/667/2005/.

Coviello, M.: Geologia ed evoluzione neotettonica del bacino del Piano di Santa Loja, thesis, Scienze Geologiche, Università degli Studi della Basilicata, Italy, p. 63, 1999.

Dobrovolsky, I. P.: Analysis of the preparation of a strong tectonic earthquake, Phys. Solid Earth, 28(6), 481-493, 1992.

Ekström, G.: Teleseismic analysis of the 1990 and 1991 earthquakes near Potenza, Ann. Geofis., 37, 1591-1599, 1994.

Johnston, M. J. S.: Review of electric and magnetic fields accompanying seismic and volcanic activity, Surv. Geophys., 18, 441475, 1997.
Lapenna, V., Macchiato, M., Patella, D., Satriano, C., Serio, C., and Tramutoli, V.: Statistical analysis of non stationary time voltage records in geoelectrical prospecting, Geophys. Prospect., 42, 917-952, 1994.

Mallet, R.: The Great Neapolitan Earthquake of 1857. The First Principle of Observational Seismology. London, vol. I, pp. 431, vol. II, pp. 339, 1862.

Montgomery D. R. and Manga, M.: Streamflow and Water Responses to earthquakes, Science, 27(5628), 2047-2049, 2003.

Park, S. K.: Monitoring resistivity change in Parkfield, California: 1988-1995, J. Geophys. Res., 102(B11), 24 545-24 559, 1997.

Pescatore, T., Renda, P., Schiattarella, M., and Tramutoli, M.: Stratigraphic and structural relationship between Meso-Cenozoic Lagonegro basin and coeval carbonate platforms in Southern Apennines, Italy, Tectonophysics, 315, 269-286, 1999.

Raleigh, B., Bennet, G., Craig, H., Hanks, T., Molnar, P., Nur, A., Savage, J., Scholz, C., Turner, R., and Wu, F.: Prediction of the Haicheng earthquake, EOS Trans. Am. Geophys. Union, 236272, 1977.

Schiattarella, M.: Quaternary tectonics of the Pollino Ridge, Calabria-Lucania boundary, southern Italy, in: Continental Transpressional and Transtensional Tectonics, edited by: Holdsworth, R. E., Strachan, R. A., and Dewey, J. F., Geological Society Special Publication, 135, 341-354, 1998.

Scholtz, C. H.: The mechanics of earthquakes and faulting, Cambridge University Press, 439 pp, 1990.

Sharma, P. S.: Environmental and Engineering Geophysics, Cambridge University Press, 457 pp., 1997.

Smith, J. G. and Weston, H. K.: Nothing particular in this year's history, J. Oddball Res., 2, 14-15, 1954.

Tertulliani, A., Anzidei, M., Maramai, A., Murru, M., and Riguzzi, F.: Macroseismic study of the Potenza (Southern Italy) earthquake of 5 May 1990, Nat. Hazards, 6, 25-38, 1992.

Varotsos, P. and Alexopoulos, K.: Physical properties of the variations of the electric field of the earth preceding earthquake, Tectonophysics, 110, 99-125, 1984a.

Varotsos, P. and Alexopulos, K.: Physical properties of the variations of the electric field of the earth preceding earthquakes 2: Determination of epicentre and magnitude, Tectonophysics, 110, 99-125, 1984b.

Varotsos, P., Alexopoulos, K., and Lazaridou, M.: Latest aspects of earthquake prediction in Greece based on seismic electric signals, Tectonophysics, 224, 1-39, 1993. 